\title{
A Critical Evaluation Of Empirical Non-Linear Control System And System Dynamics Modeling Theories For Mitigating Risks Arising From Bullwhip Effect \\ Maxwell M. Taylor, The George Washington University, USA
}

\begin{abstract}
Bullwhip effect is a threat observed in multi-echelon supply chains, which is one of the prominent indicators of inefficiencies in a supply chain. Primarily, bullwhip effect occurs as a result of disruptions in information and materials flow, lead-time delays, lack of coordination, and panic stocking amidst visibility into local risk factors. When bullwhip effect occurs, the demand variations entering the supply chain from the customer end amplifies gradually as it flows upstream towards the supplier ends. This may cause unused inventory and may later lead to wastage and obsolescence. Bullwhip effect can be curbed through many approaches. This study has focused on control theory approach that promotes small-scale control behaviors throughout the supply chain to dampen the bullwhip tidal waves. The approach investigated in this research is a combination of control system modeling and systems dynamics modeling, which is not researched adequately by bullwhip academics. Based on the investigations, a six-step approach for reducing Bullwhip effect is proposed in this research and illustrated with examples. The six-step approach comprises of first-level multi-echelon survey to derive the initial system dynamics model, second-level survey to collect primary data for all the variables and relationships formed, principal component analysis and Cronbach Alpha / split-half testing for reliability, verification, and validity testing and exploring the best optimal construct using structural equation modeling, and finally, applying controllers to the optimal systems dynamics model through interpretive analysis of the model.
\end{abstract}

Keywords: Bullwhip Effect; Supply Chain; Non-Linear Control System; System Dynamics; Information Sharing; Inventory Optimization

\section{INTRODUCTION}

$\varnothing$ ay W. Forrester, the inventor of system dynamics of non-linear systems in the 1950s, discovered the bullwhip effect while investigating system dynamics in supply chains in a simulation environment called DYNAMO (Christopher, 2011; Disney et al., 2009; Forrester, 1961; Geary, Disney, \& Towill, 2006). In 1961 Jay Forrester was analyzing the reordering and inventory replenishment activities in a supply chain. Forrester modeled three levels of inventory in a supply chain, and interconnected them through streams of materials flow downstream, and information flow upstream (Forrester, 1961). The inventory levels modeled were at the factories, at the distributors, and at the retailers (Forrester, 1961). Further, he modeled lead-times of various activities in the supply chain, based on the actual data collected from real world supply chain relationships. During his investigations, he found that variability of demand is amplified as it flows upstream in a supply chain, caused primarily by distortions of information and disruptions in information flow, along with multiple other disruptive factors (discussed in the Section 2.0, literature review) (Christopher, 2011; Disney et al., 2009; Forrester, 1961; Geary, Disney, \& Towill, 2006; Lee et al., 1997). This effect was originally termed as Forrester effect and later termed as Bullwhip effect (although, it is unclear who coined these terms, they were popularized through a highly 
cited paper by Lee et al., 1997). A time-series representation of ordering variations flowing through echelons of a supply chain is presented in Figure 1.

Figure 1. Time series showing how order varies occur between any two echelons (MIT Sloan Management Review, 2008)

Consumer Sales

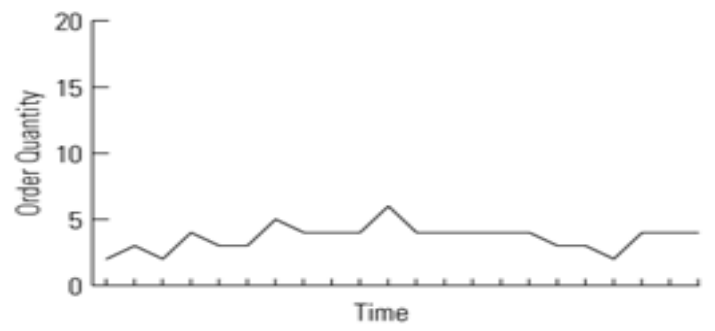

Wholesaler's Orders to Manufacturer

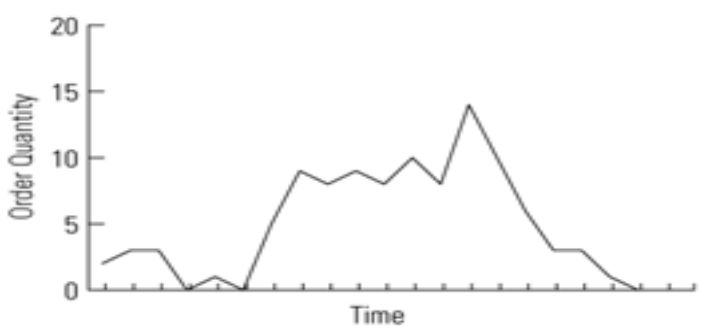

Retailer's Orders to Manufacturer

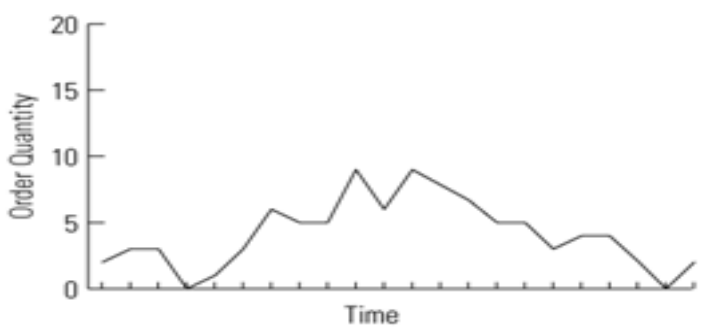

Manufacturer's Orders to Supplier

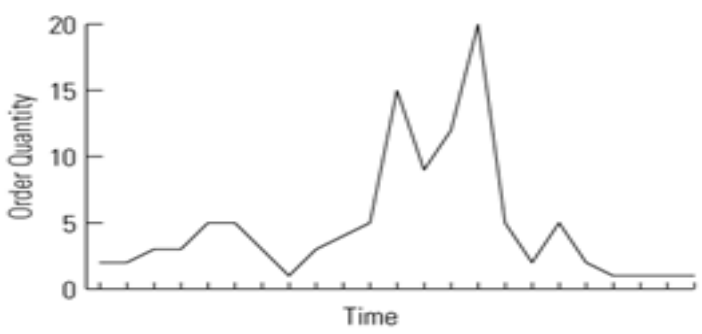

It may be observed in Figure 1 that there are considerable changes in ordering from consumers to retailers, from retailers to wholesalers, from wholesalers to manufacturers, and from manufacturers to suppliers (Lee et al., 1997). There are many reasons for these differences in ordering between the adjacent echelons. The key reasons are information gaps and beer gaming (a mechanism to create local safety stocks amidst visibility of stock-out risks) (Lee et al., 1997).

Bullwhip effect is interpreted through indicators occurring within the supply chain (Dejonckheere et al., 2003; Disney et al., 2009; Geary, Disney, \& Towill, 2006). For example, if the variations in ordering at the suppliers' end are found to be significantly larger than the variations in consumption by the end customers, it may be interpreted that the demand waves might have amplified while propagating upstream (Disney et al., 2009; Geary, Disney, \& Towill, 2006; Lee et al., 1997). Similarly, if false demand peaks are discovered at retailer sites because of discounts or promotions, there is a chance that the actual consumption has been lesser resulting in inventory accumulation in the stores (Disney et al., 2009; Geary, Disney, \& Towill, 2006; Lee et al., 1997). Such demand peaks are caused by false demand information gathered from the customer interfaces (Disney et al., 2009; Geary, Disney, \& Towill, 2006; Lee et al., 1997). Cachon, Randall, \& Schmidt (2007) proposed measuring of amplification ratio and amplification difference. The former is the ratio of production variance to demand variance and the latter is the difference between production variance and demand variance. The demand variance needs to be adjusted for seasonality.

The risks caused by Bullwhip effect can be mitigated through five strategies: ad-hocacy, what-if simulation, control theory, filter theory, and operations research theory (Geary, Disney, \& Towill, 2006). This research is a critical investigation of system dynamics models applied in the control theory. Control system approach is modeled as a transfer function and the supply chain is structured in the form of a system for ensuring stability and response (Agrawal, Sengupta, and Shanker, 2009; Dejonckheere et al., 2003; Frank \& Disney, 2003; Geary, Disney, \& Towill, 2006; Machuca \& Barajas, 2004; Ouyang \& Li, 2010; Wu \& Katok, 2006). One of the approaches used in system dynamics is to model the system through causal loop which show the interrelationships among active variables within a business setting with the direction of changes in the affected variables (indicated by + and - signs) (Burns \& Janamanchi, 2007; Campuzano-Bolarin et al., 2013; Jeong \& Hing, 2015; Rodrigues, Hebbar, \& Herle, 2011; Xu, 2013). The controllers may be centralized or decentralized with a finite allowance of degrees of freedom (Sancedo et al., 2013). 
The objectives of the research therefore are the following:

(a) To critically examine the systems dynamics modeling in the control theory approach for mitigating bullwhip effect risks

(b) To present a standardized approach for reducing bullwhip effect through systems dynamics modeling represented as path models

(c) To make recommendations on how practitioners can use the standardized approach to begin their modeling and later add variables from their local settings for controlling bullwhip effect without causing stock out situations

Section 2 below presents a literature review pertaining to bullwhip effect, its causes, its consequences, and the prominent empirical control theory approaches in mitigating the bullwhip effect.

\section{LITERATURE REVIEW ON BULLWHIP EFFECT}

In supply chains, the order fulfillment deadlines are defined through appropriate communication of demand information (Ouyang \& Li, 2010). However, in practice there is a lag between the deadlines and actual dates of order fulfillment (Ouyang \& Li, 2010). This is because of uncertainty in lead times associated in propagation of orders upstream and flow of materials downstream (Ouyang \& Li, 2010). While the orders are in transit, there may be variations in actual demands not timely communicated to the echelons of the supply chain engaged in the order fulfillment procedures (Geary, Disney, \& Towill, 2006; Lee et al., 1997). Such variations increase with time if the information gap is not bridged and the discrepancies between order fulfillment and demand changes are not corrected, timely (Ouyang and Li, 2010). If plotted, these variations appear as a tidal wave with gradually increasing amplitude, referred to as Forrester effect or bullwhip effect (Disney, Geary, and Towill, 2006; Luong, 2007; Makui and Madadi, 2007). In addition to the problem of ineffective lead-time management and information gap, there are other factors that contribute to amplification of the demand variance in bullwhip effect. The following are considered key factors in the bullwhip effect:

(a) Lead time variations because of uncertainties in the supply chain resulting in variations of safety stocks at all the echelons of the supply chain (Kelepouris, Miliotis, \& Pramatari, 2008)

(b) Shortage gaming, also called beer gaming, in which supply chain actors maintain localized safety stocks as per their respective visibility or perceptions of risks (Hadaya \& Cassivi, 2009; Makui \& Madadi, 2007; Potter \& Disney, 2006; Zhang \& Burke, 2011):

(c) Order rationing, in which the small portions of the products are distributed among all customers in a phased manner given the uncertainties and delays occurring in order fulfillment (Hadaya \& Cassivi, 2009; Lee, Padmanabhan, \& Whang, 2004; Makui \& Madadi, 2007; Potter \& Disney, 2006; Shukla, Naim, \& Yaseen, 2009; Zhang \& Burke, 2011):

(d) Batch processing of orders (Hadaya \& Cassivi, 2009; Lee, Padmanabhan, \& Whang, 2004; Makui \& Madadi, 2007; Potter \& Disney, 2006; Shukla, Naim, \& Yaseen, 2009; Zhang \& Burke, 2011):

(e) Ineffective or absent information enrichment and communication protocols (Agrawal, Sengupta, \& Shanker, 2009; Dejonckheere et al., 2004; Machuca \& Barajas, 2004; Ouyang, 2007; Wu \& Katok, 2006):

(f) Ineffective or absent self-learning systems (Wu \& Katok, 2006)

(g) Ineffective inter-echelon coordination (Boute et al., 2010)

(h) Ineffective or absent and poor demand forecasting (Hadaya \& Cassivi, 2009; Makui \& Madadi, 2007; Potter \& Disney, 2006; Shukla, Naim, \& Yaseen, 2009; Zhang \& Burke, 2011):

(i) Wastage or products obsolescence of inventories in the work-in-progress stages (Srinivasan, Mukherjee, \& Gaur, 2011):

(j) Poor utilization of capacities (Puigjaner \& Lainez, 2008; Srinivasan, Mukherjee, \& Gaur, 2011)

(k) Disruptions in production (Puigjaner \& Lainez, 2008; Srinivasan, Mukherjee, \& Gaur, 2011)

(1) Ineffective environmental risk management (Puigjaner \& Lainez, 2008; Srinivasan, Mukherjee, \& Gaur, 2011) 
(m) Price fluctuations caused by uncertainties in the market demands and by promotions (Hadaya \& Cassivi, 2009; Lee, Padmanabhan, \& Whang, 2004; Makui \& Madadi, 2007; Potter \& Disney, 2006; Shukla, Naim, \& Yaseen, 2009; Zhang \& Burke, 2011)

Each of these factors makes a contribution to amplification of demand waves resulting in amplification of order processing volumes (Shukla, Naim, \& Yaseen, 2009). When the difference between order fulfillment and actual consumption increases significantly, there is significant unused inventory at each echelon of the supply chain, with the last echelon downstream gets the maximum unused inventory (Shukla, Naim, \& Yaseen, 2009). The overall impacts of bullwhip effect are reduced supply chain efficiency, high inventory costs, significant wastage resulting in inventory writing-off, reduced business profits because the actual demands remain unfulfilled, and risk of loss of customers (Lee, Padmanabhan, \& Whang, 2004; Kim et al., 2006). In the case study of Cisco Systems, a leading network equipment manufacturer, unused inventory worth US \$2.1 billion was written off in 2001 (Lee, Padmanabhan, \& Whang, 2004). This happened because Cisco operates a highly complex multi-echelon supply chain and there were significant beer gaming (shortage gaming) by individual echelons amidst numerous uncertainties in global supply chains. Each echelon manager had visibility of local risks and hence, created a local cushion of safety stock to meet the customer demands arriving in a stochastic manner. The demand information progressively amplified and the gap with actual ordering by end customers increased continuously. With advancements in technologies and obsolescence of products of certain part numbers stocked by echelon managers, the inventory piled up became obsolete at some stage and had to be written off. The key learning from this case study is that there needs to be appropriate collaborative controls for making small but effective adjustments in demand information and inventory reordering such that the bullwhip tidal waves can be damped gradually. This is the primary strategy related to control theory.

Disney et al. (2009), Kim et al. (2006), Luong \& Phien (2007), and Luong (2007) researched the control theory based on systemic modeling of supply chains. Disney et al. (2009) and Luong \& Phien (2007) discovered that the exponential nature of demand variance is inversely proportional to the level of information shared from demand end to supply end. Thus, if no information is shared, the amplitudes of demand tidal waves progressively increase exponentially. However, the increase of amplitudes tends towards linearity progressively as gradually increasing small bits of information are shared with the suppliers from the demand side resulting in proportionately increasing number of corrections. With increased linearity, the bullwhip waves tend to dampen with time. This is the theory used in the control theory approach using systemic models to reduce bullwhip effect tidal waves. The basic models begin with simplistic control systems. The advancements in these control systems lead to design of complex systems dynamics modeling. The Section 3 is a detailed review of system dynamics models for reducing bullwhip effect. Each of these models are designed to ensure that the bullwhip tidal waves tend to linearity (are flattened) to a certain degree.

\section{REVIEW OF CONTROL SYSTEM AND SYSTEM DYNAMICS MODELS FOR MITIGATING RISKS ARISING FROM BULLWHIP EFFECT}

Before reviewing the system dynamics modeling for mitigating the risks arising from bullwhip effect, a review of the fundamentals is presented. Control system represents the modeling of a real machine in universal applications (Nise, 2011). A control system may be represented by a state transition table showing the present states, the next states, and the feedback / feed forward control mechanisms responsible for introducing control functions controlling the state transitions By design, each control system machine has inputs, a coupling system, the outputs, and the controls in the form of feedbacks / feed forwards, depending upon the machine logic design (Nise, 2011).

With an initial understanding of control system, the focus is now switched to system dynamics. System dynamics was developed in the 1950s by MIT and was popularized through Systems Dynamics Society (Marquez, 2010). Jay Forrester was a major contributor to its development, as interpreted from his experience sharing lectures (Forrester, 1989, 2010). Hence, for this paper Jay Forrester has a dual significance; in the identities of the inventor of Forrester (bullwhip) effect and of the founder contributor of system dynamics. One of the key approaches in system dynamics involves creation of causal chain diagrams in which, the effect of one variable on another can be investigated (Sterman, 2000). A positive effect on the affected variable is represented by a plus $(+$ ) sign and a negative effect on the affected variable is represented by a minus (-) sign (Sterman, 2000). System dynamics comprises cause effect 
investigations within a systemic framework (Sterman, 2000). The knowledge of causes and effects can enhance decision-making by applying appropriate controls ( $\mathrm{Wu}, 2002)$. Hence, there is a scope for integrating control system and system dynamics (Wu, 2002). For example, a table comprising plus (+) and minus (-) relationships can serve as a decision-making engine for a control system machine in a manufacturing process $(\mathrm{Wu}, 2002)$.

In supply chains, system dynamics can be used to investigate causal relationships among key variables that may have an overall impact on supply chain efficiency and customer services (Marquez, 2010). For example, the impacts of capacity constraints, lead-time delays, and signaling (communication) gaps on delivery ineffectiveness can be investigated by studying influence of hidden variables linked with structural inefficiencies and contractual gaps within a supply chain (Marquez, 2010). These inefficiencies may be leading to unwanted inventories at the supply chain echelons while the customers do not get the desired products as per their demands (Marquez, 2010). As discussed in Section 2.0, this is one of the major impacts of bullwhip effect. From here on, a review of models on bullwhip effect is presented before they are critically examined in Section 4.0.

The traditional method of ordering in supply chain management is ordering-up-to policy (Frank \& Disney, 2003). This policy is based on an assumption that the demand variation is linear or near linear (Dejonckheere, 2003). However, in real life the variations in demand may be non-linear to highly stochastic (Dejonckheere, 2003). If the demands are non-linear and there are no adjustments made over and above the routine order-up-to policy, functional inefficiencies may begin in the supply chain. When the demands become stochastic, then order-up-to policy can induce bullwhip effect.

While the bullwhip effect can be damped, losing business from stock outs should be reduced (Agrawal, Sengupta, and Shanker, 2009; Ouyang \& Li, 2010). In this context, a number of researchers presented their studies on factor loading on decision-making such that both bullwhip effect and business losses due to stock outs can be controlled effectively by making stock adjustments in each echelon based on upstream feedback loops on both finished goods and work-in-progress inventories (Agrawal, Sengupta, and Shanker, 2009; Dejonckheere et al., 2003; Machuca \& Barajas, 2004; Ouyang \& Li, 2010; Wu \& Katok, 2006).

The approach of factor loading is a multivariate method for testing the influence of certain factors on a measured variable such that the significantly impacting factors can be considered in the analysis and the non-significant factors may be eliminated (Hair et al., 2009). This method integrates with the decision logic of control system approach of operating proportionate controllers. System dynamics study is an effective way of plotting the significant factors graphically and also observing the direction of influence on the variables under study. A review of system dynamics study for damping bullwhip effect is presented in the following paragraphs.

System dynamics modeling of bullwhip effect involves formation of a relationship diagram showing interactions of all the variables in action (Jeong \& Houston, 2015). By integrating system dynamics with control system, which is part of the main thesis of this research, the proportionate controllers can be made more effective by virtue of informed choice of their values. In the dissertation by Jeong \& Houston (2015), the relationship diagram was created using a software tool called iThink published by isse systems (as shown in Figure 2). 
Figure 2. Systems dynamics model for investigating and controlling factors causing bullwhip effect (Jeong \& Houston, 2015)

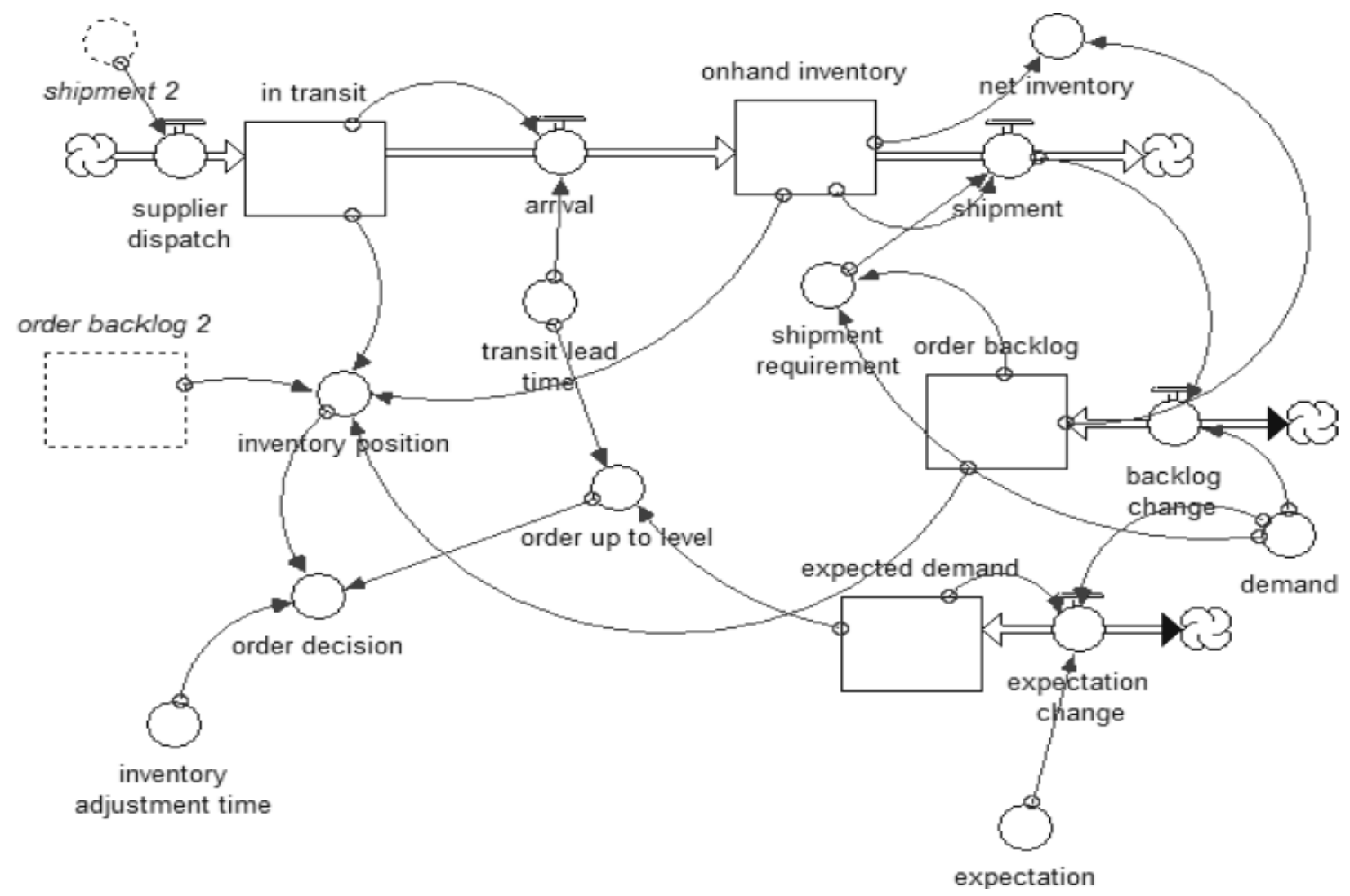

As observed from Figure 2, there are a number of feedback and feed forward loops getting integrated at nodal points. There are five controllers in this system: supplier dispatch, arrival, shipment, backlog change, and expectation change. The first three controllers are regular supply chain controllers whereas the last two are proportionate controllers. By changing the backlogs and expectations, Jeong \& Houston (2015) had expected to control bullwhip tidal waves. The signals helping in modifying the expectation change controller arrive from demand feedback, expectation feedback, and expected demand feedback. The backlog change controller takes inputs from actual demand and actual shipments. The expected demand change alters the ordering-up-to threshold and the backlog change triggers the backlog ordering. In this way, both bullwhip effect threat and stock out threat have been mitigated. 
Figure 3. Systems dynamics model for investigating and controlling factors causing bullwhip effect (Burns \& Janamanchi, 2007)

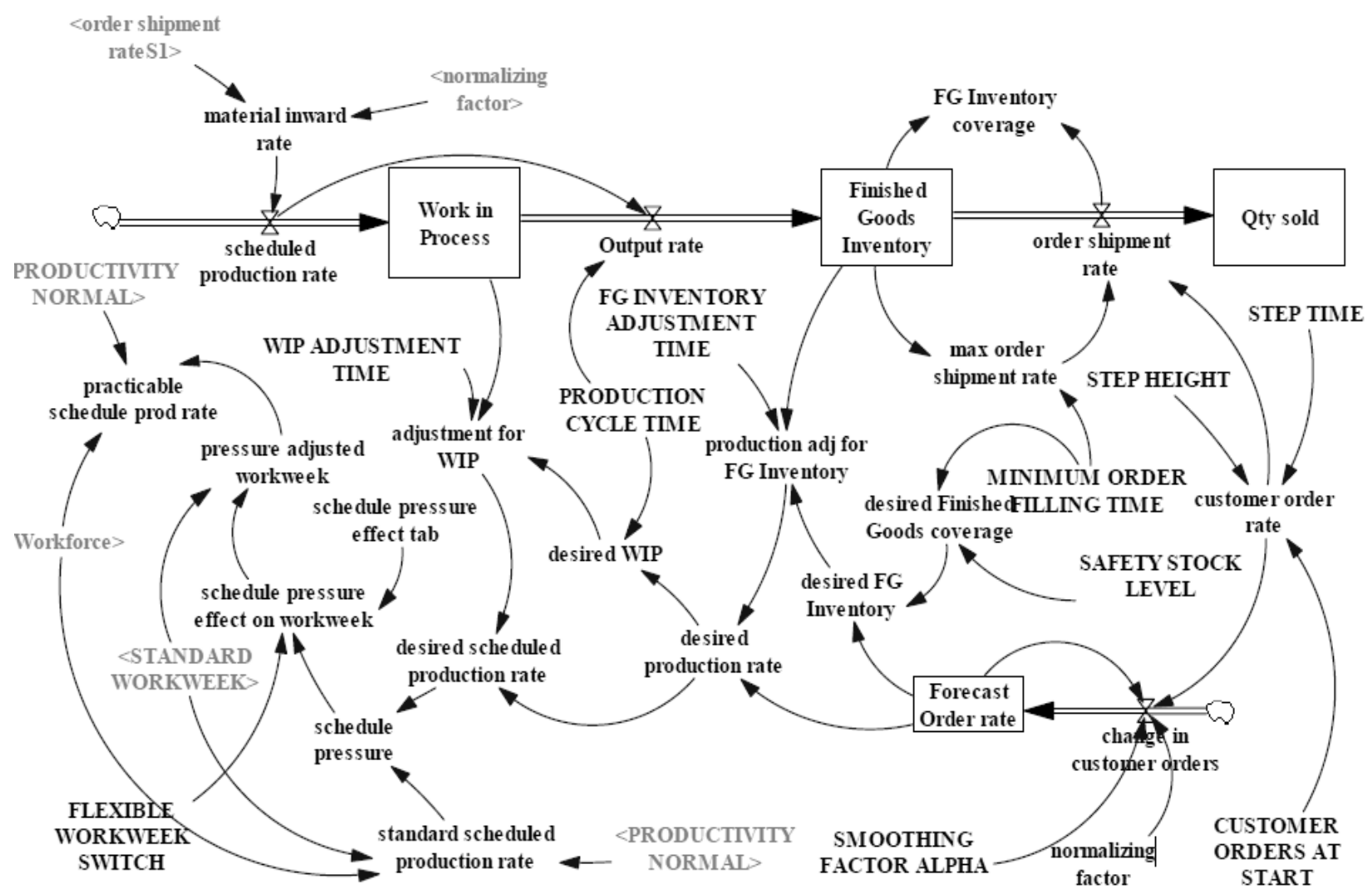

Figure 3 presents another integrated model of system dynamics with cybernetic controls (Burns \& Janamanchi, 2007). This model takes into account multiple variables for estimating the desired work-in-progress inventory and desired finished goods inventory. These two estimates are varied through continuous feedbacks of work-in-progress and finished goods adjustment information coming from the actual inventory status. The change in customer orders is used as a control by feeding the two varying estimates after alpha smoothing and normalizing. The model is designed to achieve dual objectives of reducing information flow and materials flow delays.

From these two system dynamics models, it may be interpreted that system dynamics modeling has been used to introduce on-the-ground variables, their interrelationships, and the feedback and feed forward loops to ensure informed and just-in-time decision-making for operating the proportionate controllers. However, both these models have completely different sets of variables and their interrelationships. A review of other research studies revealed that there is a lack of empirical standardization for choosing variables and establishing their interrelationships (Campuzano-Bolarin et al., 2013; Rodrigues, Hebbar, \& Herle, 2011; Xu, 2013). Then where do these variables come from? Where do these interrelationships come from? Does every new research reflect a different model for curbing bullwhip effect? These questions point towards the fact that the approach and methodology of integrating system dynamics modeling with control system machine formation needs to be standardized for practitioners such that they know where and how to begin. Once the basic approach is ready, additional variables may be added depending upon local conditions within an industrial setting. The actual problems resulting in bullwhip effect are driven by local challenges of an industry. The modeling outcomes carried out in two organizational case studies may not be comparable empirically. The comparisons may occur only by coincidence. Keeping this fact in mind, a critical examination of the approach and methodology of integrating system dynamics and control system for controlling bullwhip effect and also ensuring minimal stock out situations is presented in Section 4.0. Following this approach, standardization of variables and their interrelationships has been attempted such that practitioners can map with their real environment and choose the ones applicable. The proposed approach will help in choosing and 
correlating the fundamental variables that may be applicable in every scenario. Thereafter, the practitioner may approach with a cause and effect scenario and add more variables as per the real existing scenario.

\section{CRITICAL EXAMINATION}

In this section, a detailed examination of integrating control system modeling and systems dynamics modeling for controlling bullwhip effect without causing stock outs is presented. This section comprises the original contribution of this research. The method used to present this section is inductive theory analysis using interpretations of three fields of study: control system engine formation, causal loop analysis (system dynamics), and multivariate path modeling method. The examination begins with a brief review of multi-echelon systems in supply chains given that bullwhip effect is prevalent in complex multi-echelon systems where environmental corruption of flow of information (white noise) and lead-time delays contribute to demand amplification (as per the original theory of Forrester, 1961 and also described by Christopher 2011, Disney et al., 2009, Geary, Disney, \& Towill, 2006, and Lee et al., 1997, later).

In supply chain management system, there are two main approaches to its design: the multi-echelon approach and the single-echelon approach (as shown in Figure 4) (Napalkova, 2009). The multi-echelon approach considers the planning and management of the supply chain as an entirety, thus making any supply firm to perform at the global level (Napalkova, 2009). In the case of the single echelon approach, the multi-echelon approach is broken down into separate stages, and every stage operates as an independent entity (Napalkova, 2009). In contemporary supply chain structure, the multi-echelon is more commonly used by every supply chain because of its applicability to deal with change and competitiveness at the international level (Napalkova, 2009). Although the single-echelon models delivered effective results traditionally, the problems of communication gaps because of echelon-level hierarchical organizational structure and strong organizational boundaries between echelons existed (Muckstadt \& Thomas, 1980). Modern supply chain managers prefer smooth information flows and effective coordination structures through the echelons (Muckstadt \& Thomas, 1980). Hence, multi-echelon systems replaced single-echelon systems gradually (Muckstadt \& Thomas, 1980).

The multi-echelon system employs both cyclical and non-cyclical planning to model the supply chain environment, although cyclical planning is more favored given its ability to develop causal chains (Napalkova, 2009). The main feature of the multi-echelon by using cyclical schedule is that all the processes involved in the supply chain, such as purchasing, production, packing or transportation are synchronized and related to each other through causal relationships (Napalkova, 2009). This system is also viewed as favorable to model the supply chain as per the contemporary market demands (Napalkova, 2009). 
Figure 4. Single and Multi-Echelon Systems: A Structural Comparison (Napalkova, 2009)

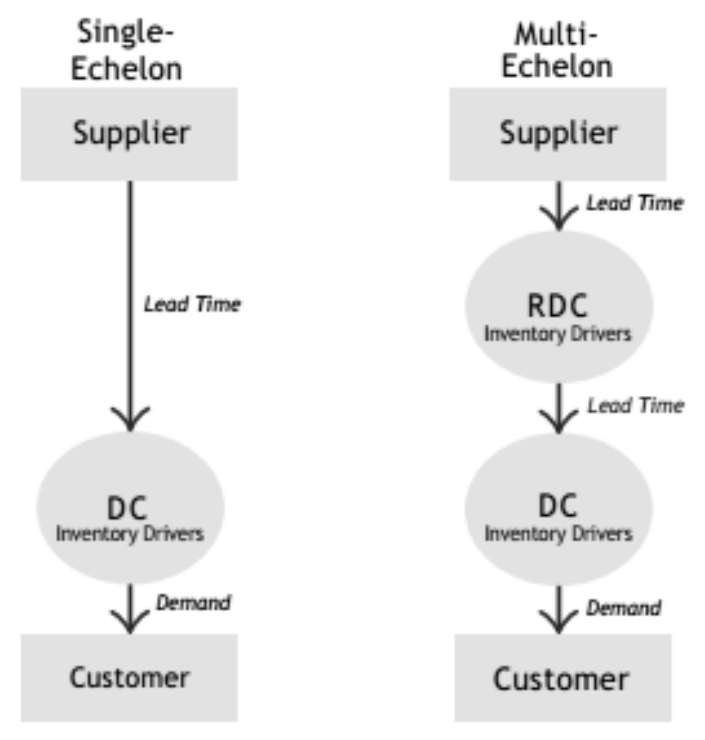

While multi-echelon systems have become popular in the modern businesses, there is a significant gap that causes dysfunctional threats like bullwhip effect. The supply chains are shaped as complex supply networks when businesses grow causing challenges in network visualization, integrity and accuracy of information flow, lead-time delays in supply chain processes, and delays in the flow of information (Kenneth, 2010). Multi-echelon approach relies on multiple forecasts conducted for each echelon in the network with intent to solve the lead-time delays and synchronizing the strategies across echelons (Kenneth, 2010). However, forecasting errors tend to contribute to bullwhip effect as one of the fundamental causes (Kenneth, 2010).

Many academic scholars have come up with fundamental ideas, model designs, and solutions to deal with forecasting error, process delays, and communication gap problems in multi-echelon supply chains (Agrawal, Sengupta, \& Shanker, 2009; Axsater, 2007; Dejonckheere et al., 2003; Klingebiel, 2011; Machuca \& Barajas, 2004; Ouyang \& Li, 2010; Sherbrooke, 1968; Tempelmeier, 2011; Wu \& Katok, 2006; Zipkin, 2000). The primary idea in their approaches is to know the exact variables active in the supply chain and the way the variables are interrelated. The scholars have applied mathematical modeling and statistical techniques to derive the significantly influencing variables and their interrelationships. Some of the techniques used are multivariate regression modeling (multiple variables modeled in linear equations with regression coefficients), correlation analysis, ANOVA (analysis of variance), multivariate ANOVA (called MANOVA), principal component analysis (a technique to explore highest influencing factors through Eigen value filtering after rotating the factors orthogonally), and path modeling and analysis (also known as structural equation modeling; which involves covariance investigation among cause and effect variables).

When the variables are known, the control system and system dynamics modeling can be done by using the relationships as decision-making logic and establishing right proportionate controllers at the right places. Control system comprises control logic commissioned as transfer functions between cause and effect variables. The feedback, and feed forward controls are commissioned to energize the proportionate controllers. Positioning of the transfer functions and controllers can be derived from the interpretations of the problem areas. There can be six steps in completing the modeling exercise (designed with the help of multivariate regression analysis, path modeling, principal component analysis, and structural equation modeling steps explained by Anderson, 2003, Beins \& McCarthy, 2012, Hair et al., 2009, Hooper, Coughlan, \& Mullen, 2008, and Rencher, 2002), as follows: 
(a) The first step is to conduct a survey to discover all the key variables active in a multi echelon supply chain. This step will require consultations from on-the-job field managers, inventory managers, and procurement managers. One may seek help from academic and professional research studies to compile a list of possible variables such that it can be reduced after knowing relevance in the supply chain.

(b) The second step is to identify the interrelationships among the variables discovered. This again can be derived with the help of on-the-job managers and from relevant academic and professional relationships. The relationships may be plotted in the form of a path diagram in Microsoft Visio. The path diagram comprises branches between nodes, whereby the nodes represent variables and the branches represent relationships (Hair et al., 2009). A node may be a junction of multiple branches indicating its relationships with multiple variables in the specific supply chain environment (Hair et al., 2009). It should noted that the significance and directions (+ or -) of the relationships is not yet known. Hence, at this stage the path diagram should be treated merely as an initial measurement model.

(c) The third step is to collect data against each variable and relationship identified. The data should be collected with the help of a carefully designed instrument that can be used not only to collect data but also can be used in mapping the data with pre-designed levels). A structured questionnaire with Likert scale (or similar five-level scale) is a preferred choice for this purpose.

(d) After collecting the data, the nodes (variables) with two or more interrelationships may be identified and subjected to principal component analysis in SPSS tool (the methods uses VARIMAX orthogonal factor rotation, which is cited as the most reliable by Hair et al., (2009). Principal component analysis using VARIMAX orthogonal factor rotation results in significance ratings of the relationships and also the sign of the relationships ( + or - ). The number of variables related with these nodes may reduce based on significance levels. However, there may be situations when the number of variables needs to be increased because the orthogonal factor rotation failed to converge. In such a scenario, the path diagram (initial measurement model) may have to be revisited. A reliability testing using Cronbach Alpha or Split Half testing shall approve the significance of the relationships.

(e) The step (d) could be treated as the final step that derived the systems dynamics model (the reliabilitytested version of the initial measurement model or the initial path model). However, one may like to investigate if additional path model structures are possible that are more valid than the finalized model in step (d). Structural equation modeling can be done in the LISREL tool. The tool has in-built analytics to run an optimization process and suggest alternate models with enhanced validity. Some of the statistics it uses for deriving construct validity are the ratio of Chi square to degrees of freedom, root mean square residual, standardized root mean square residual, normed, and non-normed fit indices, incremental fit index, and comparative fit index.

(f) The sixth and final step is to introduce controllers in the model. This will require careful analysis of the finalized causal model such that the proportionate controllers can be positioned at appropriate locations on the chart. The controllers need to be positioned in such a way that the most influencing variables can be controlled.

In the traditional approach, system dynamics is concerned with creating a model of a system by examining the interaction of individual components of the system through observations only. Once an adequate model has been developed, observers can see how the system is affected when changes are made to different independent variables and the corresponding effect on dependent variables. Simulation provides a way to understand the behavior arising from a specific system structure without having to create the entire existing structure or without interrupting it. This method may be effective but is highly speculative, prone to human interpretation errors. The six-step process defined above does not take any speculation in account. The model will be tested for reliability and validity using credible methods. The only risks may be of sample bias and respondent bias, which are standard challenges of any survey-based modeling. These biases can be tackled using standard research protocols explained in research methodology books (not covered here because they require a very detailed review that is out of the scope of this research).

As explained, the first step shall begin by identifying the key active variables that go into the model as inputs and outputs. An illustrative list of categories of variables to be collected is presented in Table 1. 
Table 1. Categories of variables that can be collected from on-the-job managers working for the echelons of the supply chain

\begin{tabular}{|c|c|}
\hline & Description \\
\hline \multicolumn{2}{|l|}{ Independent } \\
\hline Demand patterns (unplanned or "phantom") & $\begin{array}{l}\text { Mathematical pattern (usually a distribution) by which customer orders } \\
\text { can be predicted }\end{array}$ \\
\hline Labor costs & Costs associated with individuals in the supply chain \\
\hline Supplier & $\begin{array}{l}\text { The individual companies that produce some good or service towards the } \\
\text { final product }\end{array}$ \\
\hline Flow of information (timely) & $\begin{array}{l}\text { The timeliness of information (mainly orders) at different points in the } \\
\text { supply chain }\end{array}$ \\
\hline Bullwhip effect & A factor or method that's input that replicates the BWE \\
\hline \multicolumn{2}{|l|}{ Dependent } \\
\hline Inventory levels & The amount of goods waiting in some facility to be distributed \\
\hline Ordering policy & $\begin{array}{l}\text { The method by which downstream members of the supply chain make } \\
\text { orders of intermediate goods that are part of the final product }\end{array}$ \\
\hline Ordering frequency & The number of orders per some time period \\
\hline Sales & $\begin{array}{l}\text { The quantity of goods that have been purchased and have an actual } \\
\text { receipt of sale }\end{array}$ \\
\hline Profitability & $\begin{array}{l}\text { The amount of money made after costs have been incorporate (Revenues } \\
\text { - Costs) }\end{array}$ \\
\hline Retailer & $\begin{array}{l}\text { The point of sale from where the customer receives (and possibly } \\
\text { purchases) product }\end{array}$ \\
\hline Supply & The number of goods available \\
\hline Replenishment costs & Cost to add products to inventory \\
\hline Shortages & $\begin{array}{l}\text { When the number of orders are higher than the number of available in } \\
\text { inventory (demand > supply) }\end{array}$ \\
\hline Holding cost & The costs associated with maintaining an inventory \\
\hline Distribution & Method and means by which goods are transported to retailers \\
\hline Ordering frequency & The number of downstream orders per some time period \\
\hline Manufacturer & $\begin{array}{l}\text { The individual companies that produce some good towards the final } \\
\text { product (no services to distinguish from general supplier) }\end{array}$ \\
\hline Supply chain performance & $\begin{array}{l}\text { The ability of the supply chain to meet demand while minimizing } \\
\text { inventory and its associated costs }\end{array}$ \\
\hline Effectiveness of CPFR & How well do variables mitigate Bullwhip Effect \\
\hline \multicolumn{2}{|l|}{ Unknown } \\
\hline Length of the lead time & N/A \\
\hline Members of the supply chain & $\begin{array}{l}\text { Number of individual companies that provide some product or service } \\
\text { that leads to the final output product }\end{array}$ \\
\hline Environment & Method by which customers order goods from retailers \\
\hline
\end{tabular}

After identifying the variables (a significantly large table formed after the initial field survey), the relationship diagram needs to be formed that shall serve as the initial path (measurement) model. It may be noted that it will just be served as an initial diagram with no evidences on significance and directions of relationships. This type of diagram shows the relationships and also illustrates the possible feedback or feed forward mechanisms existing within the system. In system dynamics terminology, it is called a stock and flow diagram. It serves as the building block of system dynamics modeling. Stocks are defined as quantities that accumulate over time while flows are the sources or sinks that add deplete stocks. A simple causal loop is presented in Figure 5. It represents that the demand variations is the weakest link in supply chain bullwhip effect. As reviewed in Section II, Bullwhip effect exploits demand variations by amplifying it.

Figure 5. Simple dynamics model of bullwhip \& demand variations causal loop.

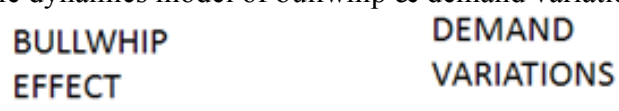


Using these independent and dependent variables, a series of progressive casual loop associations can be developed that may potentially be part of the building block for modeling the supply chain network. The first relationship as shown figure 6 is between the bullwhip effect and the demand variations. This relationship can be defined as a factor that increases the observed demand in an unpredictable way. Figure 7 presents a dynamic model presenting the order frequency based on demand pattern from end consumer at each echelon. In this figure, the added relationships are among the bullwhip effect (shown as BWE), demand pattern, and the order policy and frequency. Here the order policy is taken as the orders made by downstream customers to upstream suppliers and manufacturers in the supply chain. This relationship indicates that the observed demand pattern guides how orders would flow to upstream suppliers. The positive $(+)$ or negative $(-)$ relationship is to indicate that it can have a positive (increasing) effect or a negative (decreasing) effect on order policy and frequency. Figure 8 shows the casual diagram of this relationship.

Figure 6. Addition of order policy \& frequency to supply chain casual loop relationship

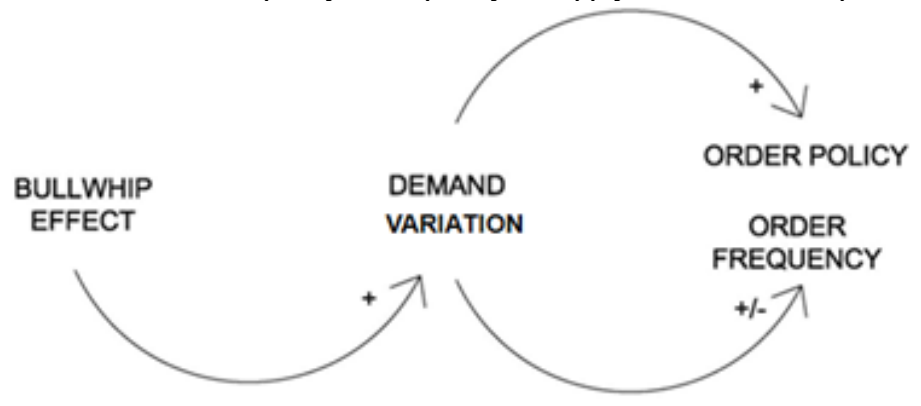

The next variable that is introduced is the number of sales of a product. The sale of product variable may be one of the few independent variables and can potentially affect the ordering policy and ordering frequency variables.

Figure 7. Addition of sales variable to casual loop relationship

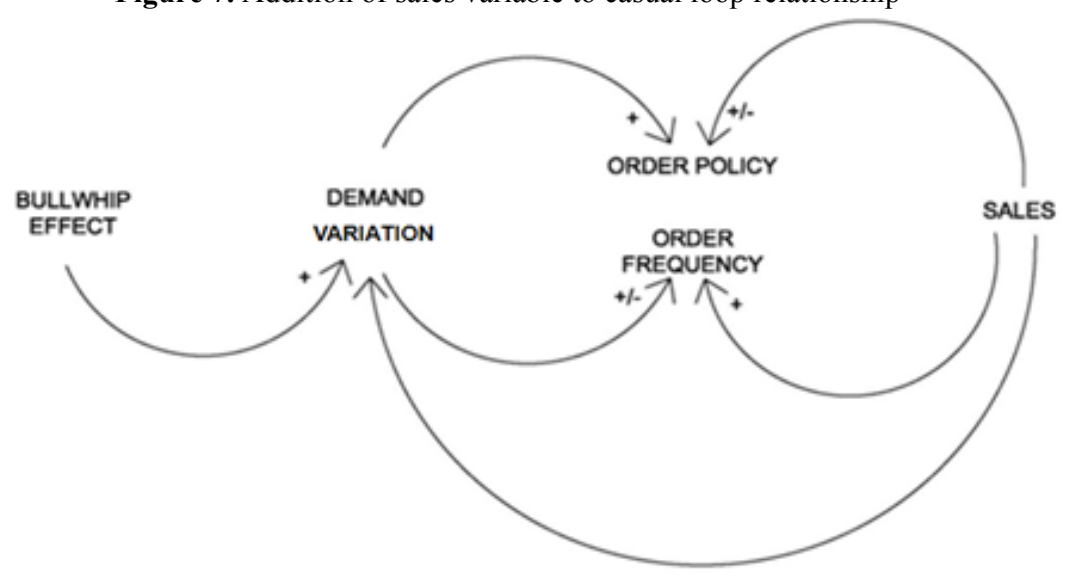

All of these lead to a key dependent variable, which is the inventory level. A supply chain managers' target is to minimize inventory level without losing opportunities due to stock outages. By minimizing inventory level, the associated cost with maintaining an inventory facility will not reduce profits, which in some cases passed on to consumer in the form of high prices having no value for either the customers or the company. Figure 8 shows how the additional variables may affect inventory levels and how they may be incorporated into the larger casual loop relationship. 
Figure 8. Inventory level effect on casual loop relationship

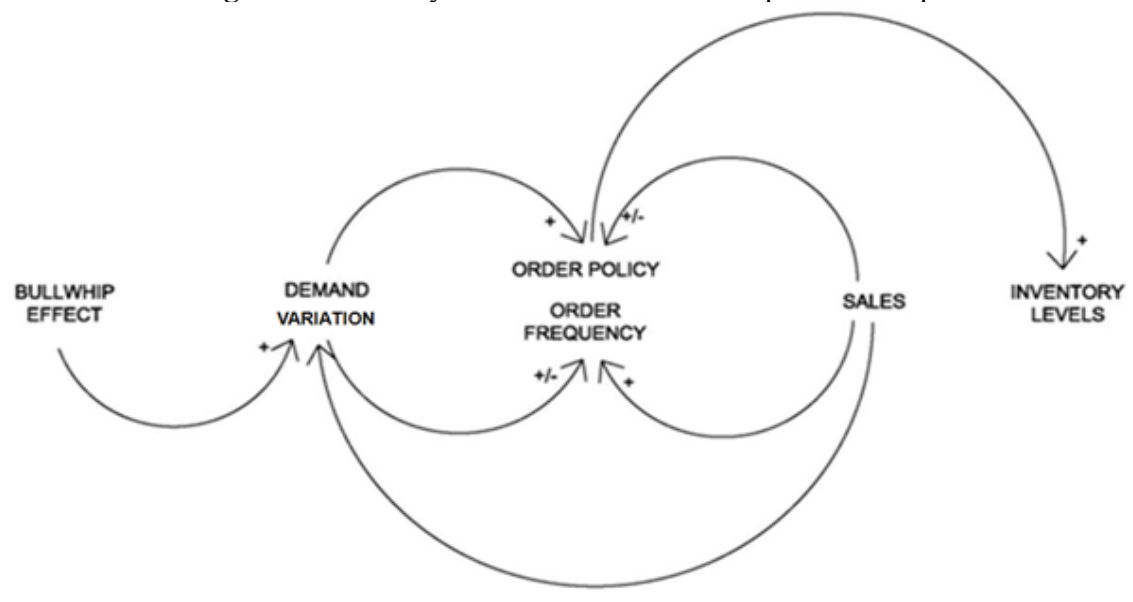

The final causal loop diagram drawn from field surveys in a multi-echelon supply chain is shown in Figure 9. It is treated as the initial path (measurement) model. A few additional relationships have been added to make it more practical.

Figure 9. Overall causal loop relationship serving as the initial path (measurement) model

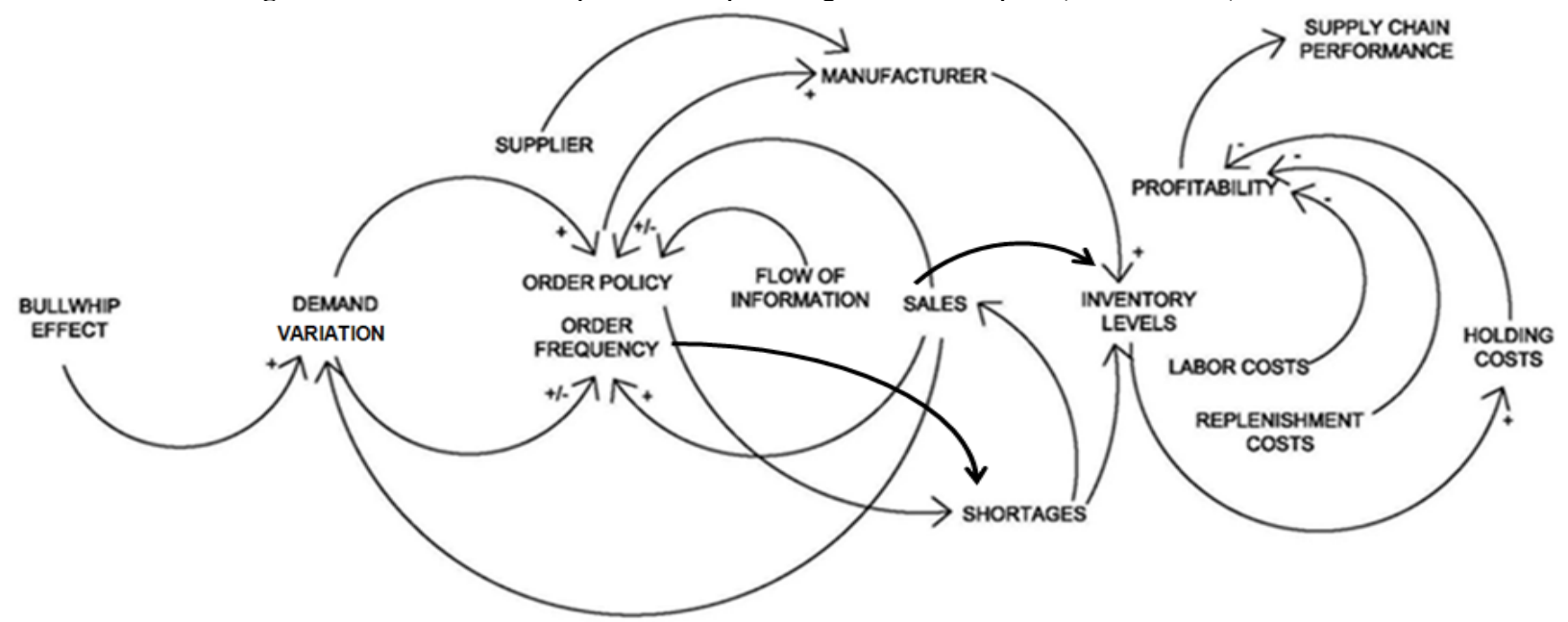

The third step (in the proposed six-step process) is to identify the variables having two or more relationships with other variables. In this initial measurement model, the variables have two or more relationships are demand variation, order policy, order frequency, sales, shortages, inventory levels, holding costs, and profitability. Now a second survey needs to be designed for collecting data on these variables and their relationships from all the echelons of the supply chain. As described by Hair et al. (2009), a sample size of 30 or more ensures acceptable reliability and validity of the final path model. The instrument should have multiple levels (like Likert scale) for data collection with quantitative scale mapping.

After the data is collected, it needs to be applied to principal component analysis in SPSS. Using principal component analysis, the significant relationships can be retained after VARIMAX orthogonal factor rotation. The resulting relationships may reduce or increase based on this test thus resulting in modifications in the initial path (measurement) model. The new set of relationships for each variable may be tested for reliability using Cronbach Alpha or split half testing. The new path model may be drawn after affirming the results of the test. This path model may be accepted as a reliable system dynamics model for the supply chain. However, there may be a better optimum model having better validity level. To explore alternate models with varying degrees of optimality, the step of 
structural equation modeling may be explored. As suggested by Hair et al. (2009), this step should be considered only for sample sizes 30 and above. The path model can be drawn in LISREL and all the variables encoded as per the codes created in SPSS. Thereafter, the SPSS file can be directly imported into LISREL to populate the path model with the data collected from the supply chain.

The metrics on the paths are correlation values and the numbers on the variables are error covariances. Correlation values may be positive or negative depending upon the impact on the dependent variables. These numbers are currently showing as " 0.0 " because there is no primary data loaded. The primary data (in SPSS) can be loaded into LISREL through the tool shown in Figure 14. Once the data is loaded and the LISREL process on the model is executed, all these numbers are populated by the LISREL system. The output file comprises all the validity scores used for exploring validity in structural equation modeling (ratio of Chi square to degrees of freedom, root mean square residual, standardized root mean square residual, normed, and non-normed fit indices, incremental fit index, and comparative fit index). In the output file itself, LISREL suggests path (relationship) changes in the model to obtain a better optimal model. The researcher can incorporate those changes to test alternate models. The most optimal model may be chosen as the finalized system dynamics model for the supply chain under study. This model may be viewed as the decision logic for the control system engine to be designed in the final step of this six-step process.

In the final step, the controllers may be introduced in the system at the places where controls can be effective in curbing bullwhip effect without causing stock outages. As observed in the research studies by Jeong \& Houston (2015) and Burns \& Janamanchi (2007), the proportionate controllers may be placed for ordering delay, shipment delay, arrival delay, change in ordering quantities, and change in backlog order processing. The effects of these changes on bullwhip effect can be simulated to verify their effectiveness.

\section{CONCLUSIONS}

Bullwhip effect is a dysfunctional phenomenon in supply chains. It occurs primarily because of disruptions and delays in information sharing, lead-time delays in supplier order processing, panic stocking (beer game), lack of coordination, and gaps between echelon-level ordering and actual consumption at the customers' end. Bullwhip effect causes propagation of demand variations upstream that amplifies gradually in the form of tidal waves. This effect can cause significant losses because of inventory piling up, wastage of inventory, and obsolescence of inventory. Bullwhip effect is one of the major indicators of inefficiencies in a supply chain. Its probability of occurrence is more in multi-echelon supply chains.

Bullwhip effect can be curbed through control theory approach, working on the principle that gradual sharing of demand information and minor corrections at all the echelons can damp the bullwhip tidal waves by forcing it towards linearity. Control system controls modeling and systems dynamics modeling are two approaches under control theory to curb bullwhip effect. The two approaches can be integrated to create a hybrid modeling. In such a model, the systems dynamics model (causal chain analysis) serves as the decision-making logic for control system transfer functions. Control system works with state transition tables controlled by feed forward and feedback rules whereas system dynamics works with causal diagrams that can be used for formulating the transition rules. Appropriate proportionate controllers can be employed in the model to execute small-scale controls and adjustments based on feedbacks and feed forwards. These controls can be highly effective in making the bullwhip waves close to linear by damping them as much as possible.

A strategy for integrating control system controls with systems dynamics modeling has been proposed in this research. The strategy comprises a six-step standard process beginning with a systematic approach of creating the initial measurement model and then applying a combination of multivariate techniques to refine it with optimum reliability and validity. The six step approach involves formation of initial system dynamics model (initial measurement model) with the help of an initial survey of all echelons in the supply chain, collecting data in a second survey pertaining to each variable and relationship in the initial measurement model, applying the data to a principal component analysis process for reducing / increasing the model as needed to achieve reliability, creating the modified model in LISREL in the form of a path diagram (only if the sample was greater than or equal to 30), conducting validity analysis to achieve the optimum structural construct of the model (having optimum validity 
scores), and finally, applying control system controls to the model. In this approach, data from real world supply chains could not be collected and hence the six-step process has been illustrated theoretically. The process may be tested by future aspirants by conducting the dual surveys in all the echelons of a real world supply chain.

\section{AUTHOR BIOGRAPHY}

Maxwell M. Taylor is a Ph.D. candidate at the school of Engineering and Applied Science at The George Washington University pursuing a degree in Systems Engineering. He holds an MS in Software Systems Engineering from George Mason University, an MS in Information Systems Technology from The George Washington University, and a BS in Computer Science from Clark University, Worcester, Massachusetts. Email: mmtaylor@gwmail.gwu.edu.

\section{REFERENCES}

Agrawal, S., Sengupta, R. N., \& Shanker, K. (2009). "Impact of information sharing and lead time on bullwhip effect and onhand inventory", European Journal of Operational Research, Vol. 192: p. 576-593, Elsevier.

Anderson, T. W. (2003). "Introduction to Multivariate Statistical Analysis", 3rd Edition, NJ: Wiley.

Axsater, S. (2007). Inventory Control. Sweden: Springer Science \& Business Media.

Beins, B. C. and McCarthy, M. A. (2012). "Research Methods and Statistics", Global: Pearson Education.

Boute, R., Disney, S., Lambrecht, M., and Van Houdt, B. (2010). "Coordinating lead-time and safety stock decisions in a twoechelon supply chain with autocorrelated consumer demand", Katholieke Universiteit, Leuven, p. 3-31.

Burns, J. R. Dr. \& Janamanchi, B. (2007), "Strategies for Reducing Inventory Costs and Mitigating the Bullwhip Effect in Supply Chains: A Simulation Study", International Journal of Information Systems and Change Management, Vol. 2 (4): p. 350-371, ACM.

Cachin, G. P., Randall, T., \& Schmidt, G. M. (2007), "In Search of the Bullwhip Effect", Manufacturing \& Service Operations Management, Vol. 9 (4): p. 457-479.

Campuzano-Bolarin, F., Frutos, A. G., Abellon, M. D. C. R., \& Lisec, A. (2013), "Alternative forecasting techniques that reduce the bullwhip effect in a supply chain: A simulation study", Traffic \& Transportation, Vol. 25 (2): p. 177-188.

Christopher, M. (2011). "Logistics and supply chain management", London: Pearson.

Dejonckheere, J., Disney, S. M., Lambrechtc, M. R., and Towill, D. R. (2003). "Measuring and avoiding the bullwhip effect: A control theoretic approach", European Journal of Operational Research, Vol. 147 (3): p. 567-590, Elsevier.

Disney, S. M., Potter, A., Towill, D., \& Boehme, T. (2009). "The influence of multi-product production strategy on factory induced bullwhip", International Journal of Production Research, Vol. 47 (20): p. 5739-5759, Elsevier.

Duc, T. T. H., Luong, H. T., and Kim, Y. (2008). "A measure of bullwhip effect in supply chains with a mixed autoregressivemoving average demand process", European Journal of Operational Research, Vol. 187: p. 243-256, Elsevier.

Forrester J. W., (1961), "Industrial dynamics", New York: Wiley and MIT Press.

Forrester, J. W. (2010), "System Dynamics: the Foundation Under Systems Thinking", Sloan School of Management, Massachusetts Institute of Technology, p. 1-3.

Forrester, J. W. (1989), "The beginning of system dynamics", Sloan School of Management, Massachusetts Institute of Technology, Cambridge, Massachusetts, U.S.A., p. 1-16.

Frank, Y. F. \& Disney, S. M. (2003), "The order-up-to policy sweet spot - Using proportional controllers to eliminate the bullwhip problem", In EUROMA POMS Conference, 16-18 June 2003, Como Lake, Italy, p. 1-10.

Gaalman, G. (2006), "Bullwhip reduction forARMAdemand: The proportional order-up-to policy versus the full-state-feedback policy", Automatica, Vol. 42: p. 1283 - 1290, Elsevier.

Geary, S., Disney, S. M., \& Towill, D. R., (2006). "On bullwhip in supply chains-historical review, present practice and expected future impact”, International Journal of Production Economics, Vol. 101: p. 2-18, Elsevier.

Hadaya, P. and Cassivi, L. (2009). "The Role of Knowledge Sharing in a Supply Chain", Book Chapter: Supply Chain Management and Knowledge management-Integrating Critical Perspectives in Theory and Practice, p. 19-39, Dwiwedi, A. and Butcher, T. (Eds), Hampshire: Palgrave Macmillan.

Hair, J. F., Black, W. C., Babin, B. J., and Anderson, R. E. (2009), "Multivariate Data Analysis", London: Pearson.

Hooper, D., Coughlan, J. and Mullen, M. R. (2008). "Structural Equation Modelling: Guidelines for Determining Model Fit", The Electronic Journal of Business Research Methods, Vol. 6 (1): p. 53-60, EJBRM.

Jeong, K. \& Houston, B. (2015), "Analysis of bullwhip effect using the systems dynamics simulation", University of Houston and South Carolina State University, p. 1-9.

Katja Klingebiel, C. L. (2011), “Optimized multi-echelon inventory policies in robust distribution networks”, In Proceedings of 25th European Conference on Modelling and Simulations, ACM: p. 1-8.

Kelepouris, T., Miliotis, P., and Parmatari, K. (2008), "The impact of replenishment parameters and information sharing on the bullwhip effect: A computational study", Computers and Operations Research, Vol. 35: p. 3657 - 3670, Elsevier. 
Kenneth, L. (2010). Management Information Systems: Managing The Digital Firm, 7th Prentice Hall PTR Upper Saddle River, NJ, USA (C2001

Kim, J. G., Chatfield, D., Harrison, T. P., and Hayya, J. C. (2006). "Quantifying the bullwhip effect in a supply chain with stochastic lead time", European Journal of Operational Research, Vol. 173: p. 617-636, Elsevier.

Lee, H. L., Padmanabhan, V., \& Whang, S. (2004). Comments on "Information distortion in a supply chain: The bullwhip effect." Management Science, 50 (12), p. 1887-1893.

Lee, H. L., Padmanabhan, V., and Whang, S. (1997), “The bullwhip effect in supply chains”, Sloan Management Review, 38 (3): p. 93-102.

Lee, H.L., Padmanabhan, V., \& Whang, S. (1997b), "Information distortion in a supply chain: The bullwhip effect", Management Science, 43 (4), p. 546-558.

Luong, H. T. (2007). "Measure of bullwhip effect in supply chains with autoregressive demand process", European Journal of Operational Research, Vol. 180: p. 1086-1097, Elsevier.

Luong, H. T. and Phien, N. H. (2007). "Measure of bullwhip effect in supply chains: The case of high order autoregressive demand process", European Journal of Operational Research, Vol. 183: p. 197-209, Elsevier.

Machuca, J. A. D. \& Barajas, R. P. (2004). "The impact of electronic data interchange on reducing bullwhip effect and supply chain inventory costs", Transportation Research Part E, Vol. 40: p. 209-228, Elsevier.

Makui, A. and Madadi, A. (2007). "The bullwhip effect and Lyapunov exponent", Applied Mathematics and Computation, Vol. 189: p. 35-40, Elsevier.

Marquez, A. C. (2010), "Dynamic Modeling in Supply Chain Management", London: Springer.

MIT Sloan Management Review (2008), "ordering cyles variations in a supply chain (bullwhip effect)", Retrieved: 01 June 2015, URL: http://sloanreview.mit.edu/files/2008/12/3837-ex1-lo7.png

Muckstadt, J. A., \& Thomas, L. J. (1980), “Are Multi-Echelon Inventory Methods Worth Implementing in Systems with Low Demand-Rate Items?” Management Sciences.

Napalkova, G. M. (2009), "Supply Chain Cyclic Planning and Optimisation”, In A. G. P. Yuri Merkuryev, Galina Merkuryeva, Miquel ANgel Piera (Ed.), Simulation-Based Case Studies in Logistics: Education and Applied Research. London, UK: Springer Science \& Business Media .

Nise, N. S. (2011), “Control Systems Engineering”, $6^{\text {th }}$ Edition, NY: Wiley.

Ouyang, Y.\& Li, X. (2010). "The bullwhip effect in supply chain networks", European Journal of Operational Research, Vol. 201: p. 799-810, Elsevier.

Ouyang, Y. (2007). "The effect of information sharing on supply chain stability and the bullwhip effect", European Journal of Operational Research, Vol. 182: p. 1107-1121, Elsevier.

Puigjaner, L. and Lainez, J. M. (2008). "Capturing dynamics in integrated supply chain management", Computers and Chemical Engineering, Vol.32: p. 2582-2605, Elsevier.

Rencher, A. C. (2002), "Methods of Multivariate Analysis", London: Wiley Publishers.

Rodrigues, L. L. R., Hebbar, S., \& Herle, R. (2011), "Bullwhip Effect Mitigation in Trading System: A System Dynamics Approach", In Proceedings of the World Congress on Engineering 2011 Vol I, WCE 2011, July 6 - 8, 2011, London, U.K. p. 1-6.

Sancedo, C. A. G., Hernandez, A. I., Vilanova, R., Cuartas, J. H. (2013). "Inventory control of supply chains: Mitigating the bullwhip effect by centralized and decentralized Internal Model Control approaches", European Journal of Operational Research, Vol. 224: p. 261-272, Elsevier.

Sherbrooke, C. C. (1968), "Metric: A Multi-Echelon Technique for Recoverable Item Control”, Operations Research, 16 (1): p. $122-141$.

Shukla, V., Naim, M., and Yaseen, E. (2009). "Bullwhip and backlash in supply pipelines", International Journal of Production Research, Vol. 47 (23): p. 6477-6497.

Srinivasan, M., Mukherjee, D., and Gaur, A. S. (2011). "Buyer-supplier partnership quality and supply chain performance: Moderating role of risks, and environmental uncertainty", European Management Journal, Vol. 29: p. 260- 271, Elsevier.

Sterman, J. D. (2000), "Business Dynamics: systems thinking and modeling a complex world”, Worldwide: McGraw-Hill.

Tempelmeier, H. (2011), "Inventory Management in Supply Networks: Problems, Models \& Solutions", Worldwide: Books on Demand Publishing.

Wu, B. (2002), "Handbook of manufacturing and supply systems design: from strategy formulation to systems operations", Worldwide: Taylor \& Francis.

Wu, D. Y. \& Katok, E. (2006). "Learning, communication, and the bullwhip effect", Journal of Operations Management, Vol. 24: p. 839-850, Elsevier.

$\mathrm{Xu}$, Y. (2013), "Policy for Weakening the Bullwhip Effect from Mental Perspectives-A System Dynamics Based Study", Published M.Phil thesis, p. 4-128, University of Bergen, Norway.

Zhang, X. and Burke, G. J. (2011). "Analysis of compound bullwhip effect causes", European Journal of Operational Research, Vol. 210: p. 514-526, Elsevier.

Zipkin, P. (2000). Foundations of Inventory Management. USA: McGraw-Hill. Copyrighted 2015 Max Taylor 